\title{
A psicologia evolucionista versus o gênero na perspectiva do construcionismo social: analisando o processo de escolha do(a) parceiro(a) ${ }^{1}$
}

\author{
Juliana Franzi ${ }^{2}$ \\ Ulisses Ferreira Araújo ${ }^{3}$
}

\begin{abstract}
Resumo: por meio de estudo bibliográfico e amparando-se em reflexões aventadas por pesquisa doutoral, o presente artigo possui os seguintes objetivos: 1) apresentar investigações localizadas no campo da Psicologia Evolucionista sobre o processo de escolha do(a) parceiro(a); 2) analisar criticamente tais estudos à luz do conceito de gênero; 3 ) arguir sobre a impossibilidade de conciliação entre as teorias do gênero - mais especificamente a partir da perspectiva do construcionismo social - e os estudos realizados na Psicologia Evolucionista. Tal argumento sustenta-se, sobretudo, no fato de que esse ramo da Psicologia dedica especial atenção ao dimorfismo sexual, acentuando, pois, os binarismos entre o masculino e o feminino. A partir deste trabalho considera-se a necessidade de reflexão sobre os atributos que atraem os sujeitos do sexo masculino e do sexo feminino no processo de escolha da(o) parceira(o). Por essa razão, o artigo finaliza destacando a relevância da educação formal como meio capaz de aportar para a reflexão crítica sobre tal escolha, bem como de desconstruir estereótipos sobre os sexos.

Palavras Chave: psicologia evolucionista, gênero, escolha, parceiro.

Abstract: through a bibliographic research and supporting itself in reflections mooted by doctoral research, this paper has the following objectives: 1) to present investigations situated in the field of evolutionary psychology on the process of partner choice 2) to critically analyze these studies in the light of gender concept; 3) to argue about the impossibility of conciliation between gender theories - more specifically from the perspective of social constructionism - and studies conducted in evolutionary psychology. This argument is mainly sustained in the fact that this field of psychology devotes special attention to sexual dimorphism, accentuating therefore the binarisms between the masculine and the feminine. From this work, it is considered the need to reflect on the attributes that attract male and female subjects in the partner choice process. For this reason, the paper ends highlighting the relevance of formal education as a means able to cooperate to critical thinking on such a choice, as well as to deconstruct stereotypes about gender.

Keywords: evolutionary psychology, gender, choice, partner.
\end{abstract}

\section{A Psicologia Evolucionista e o dimorfismo sexual}

Os estudos realizados no campo da Psicologia Evolucionista dedicam especial atenção à compreensão do dimorfismo sexual. Por tal razão, ressaltam as distinções específicas do sexo masculino e do sexo feminino, entendendo que essas diferenças são resultantes de pressões evolutivas decorrentes do fato dos homens e das mulheres assumiram distintos papéis ao longo da história. Desse modo, entende-se que machos e fêmeas acabaram por apresentar notáveis especificidades, características de cada sexo.

\footnotetext{
${ }^{1}$ As reflexões apresentadas neste artigo advêm de pesquisa de Doutorado da primeira autora, sob a orientação do segundo autor.

${ }^{2}$ Doutora em Educação pela Universidade de São Paulo e Professora da Universidade Federal dos Vales do Jequitinhonha e Mucuri - Campus JK - juliana.franzi@ufvjm.edu.br

${ }^{3}$ Professor Titular da Escola de Artes, Ciências e Humanidades da Universidade de São Paulo (USP Leste)-uliarau@usp.br
} 
Em consonância com esse pressuposto, somente para citar alguns exemplos, podemos verificar pesquisas que buscam compreender as singularidades do masculino e do feminino desde o processo de gestação (KRAEMER, et al., 2009), bem como pesquisas que visam identificar quais as particularidades na forma de brincar de meninos e meninas (MENEZES, et al., 2010).

Menezes et al. (2010) alertam que apesar da ênfase, atribuída pela Psicologia Evolucionista, nas diferenças entre os sexos, essa perspectiva não nega a relevância dos aspectos culturais. Ao contrário, a cultura assume um importante papel de "moldar" as características para cada um dos sexos, dado que a partir dos aspectos culturais ao longo da história evolutiva, entende-se que foram geradas pressões seletivas que desencadearam mecanismos cognitivos específicos para o sexo masculino e feminino. De acordo com Menezes et al. (2010), na Psicologia Evolucionista:

Não se propõe, todavia, que a cultura seja descartada a partir de evidências da relação entre produção hormonal e dimorfismo sexual (bem como outras evidências existentes na literatura da área, que indicam influências biológicas sobre o comportamento). A cultura e a ontogênese podem "diminuir, exagerar ou ainda inverter as diferenças sexuais", já que "masculinidade-feminilidade é uma das dimensões culturais fundamentais" (Luxen, 2007, p. 383). Contudo, a Psicologia Evolucionista propõe que os diferentes papéis assumidos ao longo da história evolutiva geraram diferentes pressões seletivas e, consequentemente, o desenvolvimento de mecanismos cognitivos especializados para cada sexo (Buss, 1995). Desta forma, "papéis sexuais fazem sentido sob o ponto de vista evolucionista" (Luxen, 2007, p. 391) e as hipóteses evolucionárias sobre as diferenças sexuais demonstram ter poder heurístico e preditivo (Buss, 1995) (MENEZES et al., 2010, p. 80).

A despeito desse alerta, compreendemos que os estudos realizados no campo da Psicologia Evolucionista acabaram por minimizar e, em alguns casos até mesmo desconsiderar, as construções socioculturais que permeiam os fenômenos investigados. Assim, [...] “os psicólogos evolucionistas 'super-simplificam' a cultura tomada como escolha pessoal - dissolvendo-a em seleção natural/sexual e 'mecanismos' psicológicos inatos" (MCKINNON, 2001, p. 53). A partir dessa visão crítica, explicitaremos como tal questão se evidencia nos estudos realizados sobre o processo de escolha do(a) potencial parceiro(a).

\section{O processo de escolha do(a) parceiro(a) na perspectiva da Psicologia Evolucionista}

A perspectiva evolucionista se pauta especialmente nas ideias de Charles Darwin. De acordo com o que propunha Darwin (1871), a evolução ocorre por meio da seleção natural, ou seja, através do ajustamento e adaptação dos indivíduos diante das pressões sociais e da busca pela sobrevivência. Darwin observou que a seleção natural só é possível se existe variabilidade de características entre os indivíduos de uma mesma espécie, o que permite a seleção de um atributo em detrimento de outro. Assim, alguns indivíduos, por apresentarem maior número de aspectos positivos para a reprodução, estariam mais aptos a serem escolhidos e, portanto, teriam maior possibilidade de deixar descendentes. 
Tendo em vista essa perspectiva, atuando mais especificamente na Psicologia Evolucionista, o autor norte-americano David Buss (1989), tem se apresentado como um notável colaborador no sentido de dar continuidade aos estudos de Charles Darwin.

Buss (1989) investigou os fatores que influenciam a seleção e a escolha de um(a) parceiro(a) em 37 (trinta e sete) culturas, trabalhando com categorias como boa aparência, boas possibilidades financeiras, status social favorável e castidade. Os resultados do estudo demonstraram claras distinções entre os atributos desejáveis pelos homens e pelas mulheres na escolha da(o) parceira(o $)^{4}$ : por um lado as mulheres valorizaram mais a "boa perspectiva financeira" do potencial parceiro; por outro a "boa aparência" foi mais valorizada pelos homens que pelas mulheres (BUSS, 1989). A análise dos resultados da pesquisa revelaram, na perspectiva evolucionista, as pressões sociais sofridas pela fêmea no sentido de proteger a prole - razão pela qual a mulher preocupa-se com a boa condição financeira do parceiro - enquanto que o macho, entende que a boa aparência física da mulher a coloca numa situação favorável para a reprodução, tendo maior probabilidade de assegurar a evolução da espécie.

Tais resultados, a despeito de pequenas especificidades, foram enfatizados por uma série de estudos em contexto internacional - Buss \& Barnes (1986); Buss \& Schmitt (1993); Valdez Medina, et al. (2007) - e nacional - Feres-Carneiro (1997); Gouveia, et al. (2000); Gomes e Caramshi (2007) - apenas para citar alguns desses trabalhos.

\section{Reflexões críticas sobre o processo de atração e escolha do(a) parceiro(a) na perspectiva da Psicologia Evolucionista}

Sobre os resultados de David Buss (1989), concordamos com Susan McKinnon, (2001), uma vez que a autora elenca alguns aspectos que podem ser criticados, a saber:

- o "instrumento" de pesquisa de Buss (1989) possui categorias apriorísticas, marcado por pressupostos teóricos enviesados, bem como exclui categorias essenciais para um verdadeiro estudo intercultural (MCKINNON, 2001, p. 72). Esse olhar enviesado torna-se evidente ao observarmos que ainda que Buss (1989) tenha recorrido a estudos antropológicos, como o faz com a famosa obra de Malinowisk (1973) sobre o Trobriandeses, utiliza esse trabalho para enfatizar suas concepções, mesmo havendo uma série de elementos na obra de Malinowisk que as contradiriam, como atenta McKinnon, (2001);

- dos 37 (trinta e sete) países investigados por Buss (1989), 27 (vinte e sete) sociedades são europeias ou fortemente influenciadas pela cultura europeia, o que revela o olhar etnocêntrico do pesquisador (MCKINNON, 2001, p. 74);

evolucionistas:

- os resultados de Buss (1989) são manipulados para responder às teses

Das dezoito características possíveis que a pesquisa investiga, as primeiras quatro (atração mútua, caráter de dependência, estabilidade emocional e maturidade, e disposição agradável) são elencadas na

\footnotetext{
${ }^{4}$ Ressaltamos que ao tratar sobre a escolha do parceiro na perspectiva da Psicologia Evolucionista, não estamos mencionando que esse parceiro será escolhido para fins de vivência de uma relação afetivoamorosa, pois tal teoria entende que o foco principal dessa escolha ocorre com vistas à reprodução.
} 
mesma ordem por machos e fêmeas, e as quatro seguintes (boa saúde, educação e inteligência, sociabilidade, e desejo por casa e crianças) incluem as mesmas categorias para machos e fêmeas, embora não necessariamente na mesma ordem. Nenhum destes critérios justifica a assertiva de que a preferência por determinado parceiro seja guiada por mecanismos sexualmente diferenciados do tipo destacado pelos psicólogos evolucionistas. De fato, como Buss o admite (1989, p. 13), este material sugere que as pessoas de ambos os gêneros colocam numerosos critérios acima daqueles centrais à tese evolucionista (MCKINNON, 2001, p. 73)

Podemos observar que as investigações realizadas no campo da Psicologia Evolucionista sobre a escolha do(a) parceiro(a) se limitam a descrever os resultados, sem uma análise crítica dos motivos pelos quais eles se repetem em uma série de pesquisas. Assim sendo, um primeiro passo, no nosso entender, diz respeito à necessidade do efetivo reconhecimento da construção social, cultural e histórica que leva à valorização da beleza nas mulheres e da boa perspectiva financeira nos homens. Nesse sentido, podemos observar que as mulheres, ao longo da história ocuparam um lugar desprivilegiado no mundo do trabalho, tendo nele pouco espaço ou assumindo, majoritariamente, posições inferiores em relação ao sexo masculino. Com efeito, podemos destacar a relevância que ganhou a articulação entre os estudos de gênero e os estudos sobre o trabalho, tendo se unido "em uma permanente fertilização recíproca", consoante Guimarães (2004).

Apontamos, ademais, para a valorização histórica da beleza feminina. Nessa direção, Maria Luiza Borges (2005), no campo da Filosofia, aponta para a compreensão que se fez notável durante um longo percurso histórico, fazendo-se evidente no pensamento de diversos filósofos, dentre os quais Immanuel Kant, o qual considerava que a inteligência "estraga" a mulher, tornando-a pouco atraente, sendo necessário apenas que ela se preocupasse com sua beleza 5 . Por outro lado, a inteligência seria um atributo masculino, exercendo um importante papel no sentido de atrair às mulheres. Como nos explica Borges (2005), de acordo com Immanuel Kant, uma mulher inteligente pode despertar a admiração de um homem, mas não o desejo e o amor. Segundo Borges, para o filósofo alemão: "o esforço na ciência é sublime, pesado, portanto é masculino; o sexo feminino é belo, leve [...]" (BORGES, 2005, p. 667). Assim, Kant relacionou a beleza ao universo das mulheres e considerou que a ciência é uma tarefa demasiado árdua para elas.

Tendo em vista, portanto, que os resultados encontrados nas pesquisas realizadas na Psicologia Evolucionista não são mera casualidade, senão que reflexos sociais, construídos ao longo de um percurso histórico, sobre o que se espera do sexo masculino e do sexo feminino, consideramos relevante adentrarmos no conceito de gênero, visto que este nos permitirá compreender os sexos, e a relação entre eles, como um construto social. Nessa direção, explicitaremos nossa compreensão de que não se faz possível a articulação entre as elaborações teóricas no campo da Psicologia Evolucionista e a teoria sobre as relações de gênero, no campo do construcionismo social.

\footnotetext{
${ }^{5}$ Destacamos que não se trata de considerar que o pensamento Immanuel Kant sobre a mulher era um posicionamento isolado, senão que fruto de considerações mais amplas, tecidas e compartilhadas na sociedade de sua época.
} 


\section{A Psicologia Evolucionista versus o gênero: perspectivas inconciliáveis}

Há claros intentos no sentido de se discutir de modo convergente o conceito de gênero com a perspectiva da Psicologia Evolucionista, tal como em Menezes, Brito e Henrique (2010). De acordo com as autoras, a perspectiva da Psicologia Evolucionista deve ser entendida como complementar à teoria de gênero, visto que: "Essa perspectiva integra pré-disposições biológicas à análise de influências culturais, compreendendo, como complementares, vertentes teóricas usualmente tidas como contraditórias” (MENEZES, BRITO \& HENRIQUE, 2010, p. 245).

Ora, de nosso ponto de vista, consideramos como inadequadas as tentativas de aproximação entre o campo teórico da Psicologia Evolucionista com os aportes da teoria do gênero. Essa tentativa entende como complementar o sexo (pertencente à dimensão biológica) e o gênero (pertencente à dimensão cultural) e, desse modo, retoma, por conseguinte, uma vez mais, a problemática já amplamente discutida no seio dos movimentos feministas: a ênfase nas diferenças entre os sexos, tal como se deu com o chamado "feminismo da diferença".

Com efeito, entendemos que as críticas sofridas por autora consideradas como pertencentes ao "feminismo da diferença" - especialmente as autoras norte-americanas Nancy Chodorow e Carol Gilligan - merecem ser revisitadas para enfatizarmos a impossibilidade de conciliação entre a Psicologia Evolucionista e o gênero. Contudo, ao fazermos tal retomada não estamos desconsiderando as inúmeras distinções entre as elaborações teóricas na Psicologia Evolucionista e as elaborações teóricas no chamado "feminismo da diferença".

Atentamos, nesse sentido, para o fato de que o feminismo como movimento social é um movimento moderno - decorrente das ideias iluministas, da Revolução Francesa e Americana - que impulsionou a luta por direitos sociais e políticos.

Decorrente dessa conjuntura, o termo gênero (gender) espalhou-se entre as feministas de língua inglesa ao longo dos anos 70. Consoante Louro (1997) "é através das feministas anglo-saxãs que gender passa a ser usado como distinto de sex" (p. 21). Entretanto, como explica a autora, inicialmente não havia "a pretensão de negar que o gênero se constitui com ou sobre corpos sexuados, ou seja, não é negada a biologia, mas enfatizada, deliberadamente, a construção social e histórica produzida sobre as características biológicas" (LOURO, 1997, p.21). Tal termo, portanto, buscava marcar uma contraposição ao determinismo biológico, indicando as construções sociais que se dão nas relações entre homens e mulheres. Porém, o gênero ao contrário de substituir o termo sexo, somava-se a ele, complementava-o, uma vez que marcava a dimensão cultural, enquanto que o sexo dizia respeito à dimensão natural, biológica.

Essa compreensão sofreu severas críticas. Linda Nicholson (2000) ao referirse ao "feminismo da diferença" nos ajuda a compreender como esta corrente teórica permitiu acentuar uma noção bipolar das categorias homem e mulher. Amparando-se nos estudos da literatura médica de Thomas Laqueur (1994), a autora retoma a concepção histórica de como o corpo foi tratado até o século XVIII e evidencia como a bipolaridade entre o masculino e o feminino até este momento não se fazia tão marcante. A autora explica que, a partir do século XVIII, a medicina passou a distinguir órgãos que outrora compartilhavam do mesmo nome, tanto no corpo masculino como no feminino. Essa distinção implicou uma polarização acentuada entre os sexos. Como ressalta Fausto-Sterling (2001), esse processo desencadeou uma busca intensa por se examinar qualquer indeterminação sexual, investigando-se qual o verdadeiro sexo - masculino ou feminino - oculto em aparências ambíguas.

Ao fazer tal retomada, tornando explícito como foi sendo gestada uma concepção binária dos corpos, Nicholson (2000) refere-se ao fato de o "feminismo da 
diferença" ter colaborado para enfatizar esses binarismos, classificando-os sempre a partir de características opostas. Desse modo, para a autora, o "feminismo da diferença" passou a ser feminismo da uniformidade, pautado em afirmações ahistoricas e transculturais e tornando universal uma forma de compreender o ser mulher e o ser homem.

Destarte, de acordo com Nicholson (2000), não somente se faz necessário abandonar o determinismo biológico - como de fato é preciso reconhecer que as "feministas da diferença" o fizeram ou, ao menos estabeleceram como intento - senão que abandonar também abordagens dualistas, que ora se aproveitam de certas características biológicas, ora as rechaçam. Tais posições são denominadas pela autora como "fundacionalismo biológico", ressaltando que a recusa ao determinismo biológico não implica ainda a ausência dos aspectos biológicos para se pensar as relações de gênero (MARIANO, 2005). Com efeito, no "fundacionalismo biológico" o sexo e o gênero não são vistos como opostos, pois o sexo é compreendido como pertencente à dimensão biológica e o gênero à dimensão cultural, sendo o biológico a base sobre a qual atuam os fatores sociais. Desse modo, ao contrário do determinismo biológico, no "fundacionalismo biológico", a biologia coexiste com aspectos como a personalidade e o comportamento. Assim, o modo com o "fundacionalismo biológico" lida com as diferenças - por exemplo de raça e de classe - é, segundo Mariano (2005, p. 491), limitado e problemático, pois ao tentar abordar tais diferenças acaba por cair em universalismos.

Tais reflexões permitem evidenciar que a complementaridade entre a biologia e a cultura não é considerada como um aspecto positivo no sentido de se operar com o conceito de gênero. Contudo, reiteramos: não se trata de igualar a Psicologia Evolucionista ao "feminismo da diferença". Longe de fazer tal equiparação, nosso intuito é destacar como essa complementaridade já rendeu diversas críticas, bem como de explicitar a impossibilidade conciliação entre a Psicologia Evolucionista e o gênero na perspectiva do construcionismo social.

\section{O gênero na perspectiva do construcionismo social: a desconstrução do dimorfismo sexual e da lógica binária}

Embora já mencionado em inúmeros trabalhos, não há como deixar de destacar a relevância do artigo de Joan Scott (19995), intitulado "Gênero: uma categoria útil de análise histórica". Nele Scott "sacudiu" os trabalhos feministas indicando a necessidade de se tomar efetivamente o gênero como uma categoria de análise, uma ferramenta potente no sentido de romper com os binarismos entre o masculino e o feminino. Nessa perspectiva, não bastava mais apenas uma abordagem descritiva, preocupada com mera inserção das mulheres nos fatos históricos ${ }^{6}$, mas tornava-se necessário reconhecer o caráter relacional do gênero - tratando-o como "um elemento constitutivo de relações sociais baseadas nas diferenças percebidas entre os sexos" (SCOTT, 1995, p. 86) - e as relações de poder que por ele são tecidas, entendendo, pois que "o gênero é uma forma primária de dar significado às relações de poder" (SCOTT, 1995, p. 86).

Amparando-se nos aportes de Jacques Derrida, e reconhecendo a relevância da linguagem como meio para romper com os binarismos, Scott (1992) remete-se à relevância do método da desconstrução. Para a autora, esse método permite analisar como se constroem os significados, bem como rever e deslocar a construção

\footnotetext{
${ }^{6}$ Como observa Scott: "minha compreensão sobre a Revolução Francesa não muda por saber que as mulheres dela participaram" (SCOTT, 1995, p. 74).
} 
hierárquica das oposições binárias, expondo a limitação dos termos e reconhecendo-os como uma construção social e cultural. Segundo explica Joan Scott:

Desconstruir implica analisar as operações de diferença nos textos, e as formas como os significados são trabalhados. O método consiste em dois passos relacionados: a inversão e o deslocamento das oposições binárias. Esse duplo processo revela a interdependência de termos aparentemente dicotômicos e como seu significado se relaciona com uma história particular. Mostra como as oposições não são naturais, senão que construídas; e construídas para propósitos particulares em contextos particulares (SCOTT, 1992, p. 90-1).

De modo semelhante, Judith Butler (2003), também se amparando nas ideias de Jacques Derrida, considerou a necessidade de recusar a oposição sexo/gênero, uma vez que o próprio corpo é uma construção social e o sexo é constituído discursivamente e culturalmente. Nessa direção, como explica Mariano (2005) ao referir-se ao pensamento de Butler (2003), é preciso ter em vista que há um discurso hegemônico que valoriza a heterossexualidade - ao reconhecer apenas o masculino e o feminino - e acaba por promover a invisibilidade dos sujeitos que se distanciam da heteronormatividade.

Tendo em vista essa crítica à heteronormatividade, e voltando para os estudos sobre a escolha do parceiro na perspectiva da Psicologia Evolucionista, destacamos que - a despeito do conhecimento do trabalho de Ferés-Carneiro (1997) que chega a abordar as escolha entre parceiros homossexuais - podemos observar que são raras as investigações nesse ramo da Psicologia que ampliam a amostra da pesquisa de modo a abarcar sujeitos com distintas orientações sexuais. Contudo, para além desse ponto frágil, consideramos que o gênero tomado como categoria de análise, nos permite discutir diversos dos resultados apontados pelos psicólogos evolucionistas em seus estudos e pesquisas sobre a escolha do parceiro.

\section{Gênero e educação: novas possibilidades para se pensar a escolha do parceiro afetivo-amoroso}

Retomando a crítica de McKinnon (2001) sobre o trabalho de David Buss (1989), relembramos a relevância indicada pela autora no sentido de se evitar um olhar enviesado para a compreensão da escolha do parceiro. Nesse sentido, em consonância com os aportes do conceito de gênero na perspectiva do construcionismo social atentamos para a problematização das relações de poder que se tecem entre os sexos, dado que as categorias trabalhadas por Buss (1989) não podem ser tomadas como isolada em si próprias, pois envolvem construtos sócio-históricos que as marcam. Assim, enfatizamos, como já mencionado anteriormente, que a boa perspectiva financeira e a boa aparência denotam distintas construções para o masculino e o feminino. Dito de outro modo, podemos afirmar que não é o mesmo pensar os aspectos financeiros, a beleza e a aparência física para os homens e para as mulheres. Há significados atribuídos socialmente que podem e merecem ser refletidos.

Apontamos, pois, para a relevância da educação formal, atentando para o seu potencial no sentido de permitir a discussão sobre as relações de gênero e sobre a escolha do(a) parceiro(a).

Ao assumir tal trabalho, a escola admite, como consequência imediata, um compromisso ético, na medida em que toca em valores íntimos e muitas vezes 
inconscientes, dado que a escolha do(a) parceiro(a) foi compreendida historicamente como algo que nos acontece sem que tenhamos a possibilidade de intervir de modo racional (MORENO \& SASTRE, 2010). Esse trabalho educativo requer promover a revisão e a desconstrução da naturalização da mulher como necessariamente bela e pouco inteligente e do homem como necessariamente detentor de recursos financeiros, apenas para citar algumas das questões a serem debatidas. Com efeito, a relevância de se discutir esses estereótipos expressa-se, sobretudo, pelos riscos advindos do estabelecimento de relações de poder entre o homem - provedor dos recursos econômicos - e a mulher - frágil e dependente. Nesse sentido, vale destacar que a violência contra a mulher encontra na dependência econômica uma potente aliada para se perpetrar (MOURA, NETTO, SOUZA, 2012).

Destacamos ainda que se efetivamente há comprometimento em reconhecer as construções socioculturais que permeiam a escolha do(a) parceiro(a), é preciso observar que esse processo está marcado por uma série de expectativas em torno do amor, uma vez que, especialmente a partir do século XVIII e mais notavelmente nas sociedades ocidentais, essa escolha está envolta de idealizações e de crenças românticas que vão muito além do intuito da mera reprodução (ARAÚJO, 2002, FELIPE, 2007) Destarte, concordamos com a crítica de Jane Felipe (2007), uma vez que a autora aponta que a escola, ao trabalhar com o tema da orientação sexual, tem se restringido a prescrever e impor ações, principalmente no sentido de se evitar a gravidez precoce e doenças sexualmente transmissíveis, entretanto, pouco tem se preocupado em abordar o tema do amor, desconsiderando o potencial de um trabalho que questione, reflita, compreenda e oriente as escolhas e vivências amorosas dos jovens (FELIPE, 2007).

Desse modo, à guisa de conclusão, ressaltamos a necessidade de um trabalho pedagógico que contemple a discussão sobre a escolha do parceiro afetivo, amoroso e/ou sexual, permitindo aos alunos e alunas desconstruir estereótipos em torno da masculinidade e da feminilidade, refletir sobre as construções sociais em torno do amor e da sexualidade e orientar no sentido de promover escolhas críticas e responsáveis do(a) parceiro(a) afetivo-amoroso.

\section{Referências:}

ARAÚJO, Maria de Fátima. Amor, casamento e sexualidade: velhas e novas configurações. Psicol. cienc. prof., Brasília, v. 22, n. 2, jun. 2002.

BORGES, Maria de L. Gênero e desejo: a inteligência estraga a mulher? Rev. Estud. Fem., Florianópolis, v. 13, n. 3, Dec. 2005.

BUTLER, Judith P. Problemas de gênero: feminismo e subversão da identidade. Rio de Janeiro: Editora Civilização Brasileira, 2003.

BUSS, David M. Sex differences in human mate preferences: Evolutionary hypotheses tested in 37 cultures. Behavioral and Brain Sciences, 1989.

BUSS, David M.; BARNES, Michael. Preferences in human mate selection. Journal of Personality and Social Psychology, 1986, v. 50(3), p. 559-570.

BUSS, David.; SCHMITT, David. P. Sexual strategies theory: An evolutionary Perspective on human mating. Psychological Rewiew, 1993, 100, 204-232 
DARWIN, Charles. The descent of man and selection in relation to sex. London: Murray, 1871.

FAUSTO-STERLING, Anne. Dualismos em Duelo. Cadernos Pagu, n. 17/18, 2001, p.9-79.

FELIPE, Jane. Do amor (ou de como glamourizar a vida): apontamentos de uma educação para a sexualidade. In: Anais do III Seminário Corpo, gênero, sexualidade discutindo práticas educativas. Porto Alegre: UFRGS, 16-18 de maio, 2007, 1-20.

FERES-CARNEIRO, Terezinha A. escolha amorosa e interação conjugal na heterossexualidade e na homossexualidade. Psicol. Reflex. Crit., Porto Alegre, v. 10, 1997.

GOMES, Gizelle R; CARAMASCHI, Sandro. Valorização de beleza e inteligência por adolescentes de diferentes classes sociais. Psicol. estud., Maringá, v. 12, n. 2, Aug. 2007

GOUVEIA, Valdiney V. et al . Correlatos valorativos de atributos desejáveis de um/a parceiro/a ideal. Psicol. Reflex. Crit., Porto Alegre, v. 23, n. 1, Apr. 2010.

GUIMARAES, Nadya Araujo. Gênero e trabalho. Rev. Estud. Fem., Florianópolis , v. 12, n. 2, Aug. 2004.

KRAEMER, B., et al. Finger length ratio (2D:4D) in adults with gender identity disorder. Archives of Sexual Behavior. 2009, 38, 359-363

LAQUEUR, Thomas. La construcción del sexo: cuerpo y género desde los griegos hasta Freud. Madrid: Cátedra, 1994.

LOURO, Guacira Lopes. Gênero sexualidade de educação: uma perspectiva pósestruturalista. Petrópolis, RJ: Vozes, 1997.

MALINOWSKI, Bronislaw. Sexo e Repressão na Sociedade Selvagem. Petrópolis: Ed. Vozes, 1973.

MARIANO, Silva Aparecida. O sujeito do feminismo e o pós-estruturalismo. Estudos Feministas, Florianópolis, v. 13 n.3, dez. 2005, p. 483-506

MENEZES, Aline Beckmann; BRITO, Regina Célia Souza; HENRIQUES, Alda Loureiro. Relação entre gênero e orientação sexual a partir da perspectiva evolucionista. Psic.: Teor. e Pesq., Brasília, v. 26, n. 2, June 2010 .

MENEZES, Aline Beckmann de Castro, et al. Compreendendo as diferenças de gênero a partir de interações livres no contexto escolar. Estudos de Psicologia, 15(1), Janeiro-Abril/2010, 79-87.

MCKINNON, Susan. A obliteração da cultura e a naturalização da escolha nas confabulações da psicologia evolucionista. Horiz. antropol., Porto Alegre , v. 7, n. 16, Dec. 2001.

MORENO, Montserrat M; SASTRE, Genoveva V. Cómo construimos universos: amor, cooperaccion y conflicto. Barcelona: Gedisa Editorial, 2010.

MOURA, M. A. V.; NETTO, L. A.; SOUZA, M. H. N.. Perfil sociodemográfico de mulheres em situação de violência assistidas nas delegacias especializadas. Esc Anna Nery. 2012 jul -set; 16 (3):435 - 442

NICHOLSON, Linda. Interpretando o gênero. Estudos feministas, Florianópolis v.8 n.2 p.9-42, 2000. 
SCOTT, Joan. Igualdad versus diferencia: los usos de la teoria postestructuralista. Debate Feminista, Mexico D.F., v.5, p.85-104, mar.1992.

W. Gênero: uma categoria útil de análise histórica. Educação \& Realidade, Porto Alegre, n. 20, v. 2, p.71-100, jul./dez. 1995.

VALDEZ MEDINA, José Luis et al. La elección real e ideal de pareja: un estudio con parejas establecidas. Interam. j. psychol., Porto Alegre, v. 41, n. 3, dez. 2007.

Recebido para publicação em 15-05-15; aceito em 21-06-15 